\title{
The Role of Social Networks in
}

\section{Knowledge Sharing: A case Study of}

\section{an Egyptian University}

\author{
Dr. Ahmed Abdelkader*
}

(*) Dr.Ahmed Abdelkader isa lecturer in the Business Administration department, the Faculty of Commerce, Damietta University, Egypt. Currently, He is an assistant Professor and head of the department of Marketing, Faculty of Business Administration, Tabuk University, Saudi Arabia. He obtained his $\mathrm{PhD}$ in Marketing in 2010 from the University of Huddersfield Business School, UK. He is an active member of the Chartered Institute of Marketing CIM, Institute of Direct \& Digital Marketing, and the Global Marketing Forum.His research interests include Relationship Marketing, Knowledge Management, Services Marketing, Corporate Social Responsibility, and Electronic Management.

E-mail: aabdelkader@ut.edu.sa 
Abstract: Social Networks(SNs) offer a great potential as an alternative method to manage and share knowledge within the higher educational sector. This research therefore explores the role of SNs in Higher Education (HE) with empirical investigation of one of the Egyptian Universities i.e. Mansoura University. To gain a better understanding of the potential drivers and barriers to the use of SNs as a knowledge sharing (KS) tool within university education, a case study approach has been used. This approach consisted of semi-structured interviews with 32 membersof staff, both senior officials and academic staff, within Mansoura University Faculty of Commerce. The results indicate that there are both areas of agreement and difference in the views of participants. Issues of culture appear to affect the participation of female staff in using SNs. However, there appears to be wider differences relating to the existence of KS strategies, the extent to which staff understand the nature of SNs and technology in general and the extent to which Senior Officials and other staff views are shared. Overall the results suggest that university education in Egypt is well prepared for the use of SNs as a KS tool and some usage appears to already be occurring.

Keywords: social networks, case study, higher education, knowledge sharing, Egypt

تقدم شبكات التواصلي: العربل الاجتماعي إمكانات كبيرة كطريقة بديلة لإدارة وتبادل المعرفة في قطاع التعليم العالي. ولذلك، فإن هذالبحث يستكثف دور هذه الثبكات فيقطاع التعليم العالي من خلال در اسة مبدانية في واحدة من الجامعات المصرية. تم استخدام أسلوب دراسة الحالة من أجلال حصول فئل على فهم أفضل للمحفزات المحتملة والعوائق التي تحول دون استخدام شبكات التواصل الاجتماعي كأداة لتبادل المعارف داخل الجامعات. قام

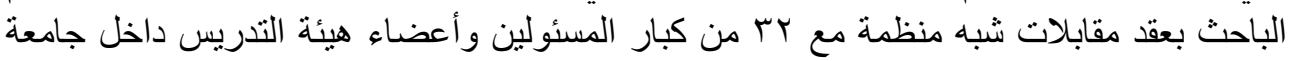
المنصورة في مصر. ونتير النتائج إلى أن هناك مجالات إتفاق واختلاف في وجهات نظر المشاركين. ومع ذللك، يبدو أن هنالك اختلافات واسعة فيما يتعلق بوجود استر اتيجية محددة لتبادل

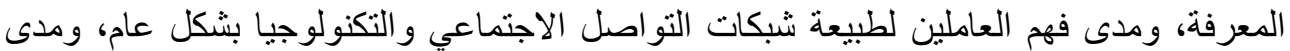
اشتر اك المسئولين و أعضاء هيئة التدريسفي وجهة نظر موحدة. عمومأ تشير النتائج إلى أن التعليم الجامعي في مصر على إستعداد جيد لاستخدام شبكات التو اصل الاجتماعي كأداة لتبادل المعرفة. كلماتـالبحث:الثبكات الاجتماعية، در اسة الحالة، التعليم العالي، تبادل المعارف، مصر 


\section{Introduction}

Knowledge is a refined form of information that has been integrated that constitutes an important personal and organisational asset that contributes to core competencies, competitive advantages, and value creation (Lin \& Lo, 2015). Nevertheless, knowledge usually resides within employees and is not always readily available to those who need it. Therefore, organizations in general, and universities in particular in the context of this research need to seek effective mechanisms for encouraging knowledge sharing.

Furthermore, global recession, increased competition, globalisation, technological advances and demand for increasing educational quality are all leading to a need for education institutions across the world to become increasingly competitive, efficient and innovative (Mathew, 2010; Torres et al., 2013). Therefore, the education sector face an increasingly challenging period.

Within this context, Knowledge Management (KM) represents an important area of consideration in terms of capturing, organizing and sharing organisational knowledge (Liao et al., 2004; Garcia et al., 2011; Lin \& Lo, 2015) to maximise and fully exploit the intellectual assets institutions hold. In this regard, Social Networks (SNs) offer great potential to share organisational knowledge within educational institutions as they allow for the capturing of tacit knowledge and allowing Knowledge Sharing (KS) to occur, which in turn provides greater opportunities for creating new knowledge and innovative practices (Ellison et al., 2015).

SNs also appear to have a substantial impact specifically within the modern Arab World with their political, social, and cultural influence. Facebook still holds the pole position among other SNs usage in Arab countries as figure 1 depicts recent statistics to compare and rank popular SNs usage in a sample of the Arab world countries. Figure 2 also shows that Egypt comes first among Arab countries in terms of the number of Facebook users. 
Figure 1: Social Networking in the Arab World

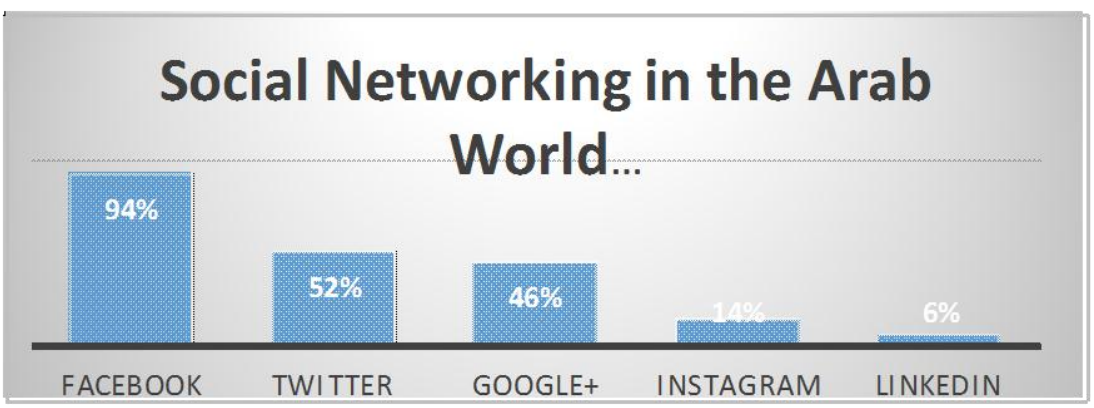

Source: Northwestern University in Qatar, (2013)

Figure 2: Middle East and North Africa's (MENA's) top five Facebook communities source MENA'S TOP FIVE FACEBOOK COMIMUNITIES

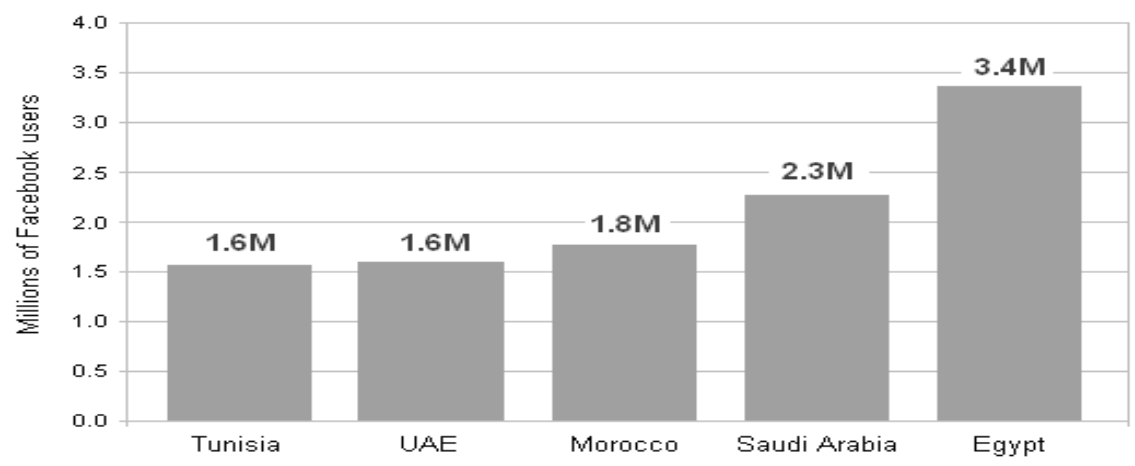

Source: Spot on PR (2010)

Based on recent statistics, the largest number of Facebook users exist in Egypt followed by Saudi Arabia and in both cases SNs have been used to mobilize collective action toward breakthroughs in social, educational, economic and political contexts. Notably, whilst there is an increasing number of Muslim based SNs, they appear to have relatively low membership and are not a preferred means of networking for the majority of the Arabic population. (Dashan, 2011). The majority of Arabic users appear to prefer sites such as Facebook which have promoted international use through marketing and the provision of more than53 translations of the site. (Facebook, 2014). 


\section{The role of SNs in $\mathrm{KS}$ in university education}

Contemporary universities serve not only as a research institutions and teaching centres, but also have additional roles. Specifically, social roles are becoming an inherent part of higher education, hence fulfilling one of their goals as defined upon their foundation; i.e. to effectively disseminate knowledge within the society (Garcia et al., 2011; Forkosh-Bauruch \& Hershkovitz, 2012; Lin \& Lo, 2015).

As the world is changing into a knowledge society, higher education is also changing and adapting to this new reality in which knowledge is acquired not only traditionally via curriculum-based, face-to-face courses or traditional classes, but also rather through diverse and varied means. In this regard, Knowledge Management (KM) and Knowledge Sharing (KS) have been the subject of much research in recent years. KM can largely be defined from two perspectives. The first has its roots in the concepts of Artificial Intelligence (AI) and subsequent Information Systems (IS) developments. This perspective relies on the ability to codify knowledge in order to share it (Snowden, 2005; Barnes, 2007) and therefore relies on knowledge in explicit form, not dealing with tacit forms (Hildreth \& Kimble, 2002; Schutt, 2003; Lin \& Lo, 2015).

The process by which tacit knowledge can be shared is therefore the subject of the second perspective of $\mathrm{KM}$ which is particularly relevant where products are largely intangible and often shared through a process of socialisation. (Nonaka \& Takeuchi, 1995).It is therefore the nature of SNs as a popular web 2.0 tool which encourages and supports socialisation that makes systems such as Facebook a relevant proposition for KM.

In terms of KS the main benefit from SNs is the manner in which they would let us see who knows what, who does what and even who controls what and update us continuously on all of these fronts (Donath, 2007; Lin \& Lo, 2015). Additionally, the popularity of existing sites suggests that, the use of SNs would be relatively straight forward.

However the motivation for existing use may not always be compatible with organisational $\mathrm{KM}$ and may lead to conflicted motivation for continued use ultimately affecting the ability of KS to occur (OFCOM, 2008). The main issue is 'what makes a social network function isn't so much the tools as it is the attitude you've got to have to "want to" and that isn't something you can get out of a box' (Suarez, 2007; Ellison et al., 2015).In terms of existing users the motivation to use SNs as a tool for KS may not necessarily be 
compatible with primary usage (Ardichivilli, et al., 2003; Forkosh-Baruch \& Hershkovitz, 2012).

Further important factors affecting the motivation for SNs use will relate to the desire for individuals to have ownership, trust and privacy of their information and knowledge. For non-users, privacy concerns will largely relate to issues of personal safety (Hewitt \& Forte, 2006) and a desire not to share personal information with a wide group, particularly if they are not chosen but due to shared organisational connections. Furthermore privacy concerns could relate to the sharing of proprietary information or even libellous or defamatory comments across the internet which could prove to be a problem both individually and organisationally.

In terms of KS, barriers may also exist from the fundamental way in which these sites operate. Information posted can become the property of the software company and therefore its unauthorised reuse cannot be guaranteed (Jones \& Soltren, 2005; Schonfeld, 2009). Any information posted is also persistent and accumulative making it searchable, replicable and available to any number of invisible audiences for an indeterminate period of time (Cain, 2007; Barnes, 2007, Dwyer et al., 2007).McConnell (2008) however considers that there is a great deal of "paranoia" concerning the privacy and inappropriate use of personal data on the internet and a balanced view of these issues is required.

Whilst a number of barriers are considered perhaps the most prevalent area for consideration must be the nature of relationships and specifically the manner in which weak ties can be utilised and strengthened through the use of a SNs (Donath, 2007; Boyd \& Ellison, 2007).The strength of weak ties within a $\mathrm{SN}$ are likely to lead to a large network especially where existing users already hold a personal network of friends and family. However it is important also to consider that networks can become too large and unmanageable. Donath (2007) places the maximum number of relationships an individual can have at 150 . In a large organisation this could be easily exceeded when considering that the average Facebook user will already have 120 confirmed friends (Sandberg, 2009).

The nature of organisations and the limited maximum number of relationships could lead to the creation of silos as homogenous groups remain separated and offline relationships are simply replicated online, no further enhancing KS or communication across the organisation (Boyd \& 
Ellison, 2009). In addition there are likely to be a number of individuals who are less familiar with technology and who may become segregated from the KS activities of the organisation resulting in a lack of completeness across the organisation. The nature of technology acceptance and use represents a fundamental barrier to the use of SNs as a $\mathrm{KM}$ tool and indicates the need for adequate training, technical support and senior management support to ensure that individuals who may not traditionally use SNs will be encouraged to trial use within an organisational context.

\section{Research Problem and Question}

The problem of the study is to assess the possibility of using modern technology in the form of SNs in the process of sharing valuable knowledge among students and staff within Mansoura University.

This study intends to answer the following research question that reflects the problem of the study: What role can social networking sites play in the university education in terms of knowledge sharing? The answer to this question tackles three fundamental issues, they are:

- The existence of aKS strategy by using SNs in the University education;

- The acceptance of use of SNs in knowledge sharing in a university context; and

- The motivation for use of such technology.

\section{Research Methodology}

Several previous studies have used a qualitative approach to identify the barriers to the use of SNs as a KM tool (i.e. Ardichvili \& Wentling, 2003; Hewitt \& Forte, 2006; Cain, 2007; Garcia et al., 2011). This approach is most appropriate due to the assumption that access to the reality of a situation is only possible through social construction (Smith et al, 2008). A qualitative approach seeks to answer questions posed by studying different social settings. As noted by Berg (2009) \& Yin (2009) qualitative techniques make it possible for researchers to participate in understanding and perceiving others, as well as permitting them to discover how people structure their daily lives to make them more meaningful. According to Creswell \& Clark (2011) the advantages of utilising this approach are numerous:

1. It provides a suitable means of studying complex phenomena. 
2. It attempts to interpret and describe people's personal experiences of phenomena.

3. It tries to understand the process of interaction between individuals.

4. It allows participants to share their views.

Therefore the validity of the results of this approach is high (Creswell, 2009).

\subsection{Case study}

Case studies are increasingly used as research tools (Creswell, 2009) and according to Yin (2009) investigate holistically and feature real-life events. Moreover, case studies are uniquely strong as they are able to deal with a variety of evidence, i.e. documents, interviews, etc. (Saunders et al., 2009), thus providing a more detailed view of the issue under consideration (Yin, 2009). In addition Siggelkow (2007) indicates that case studies are beneficial in order to understand the significance of the research questions posed and to encourage new ideas. In order to investigate the role of SNsin KS within the HE sector, a case studyapproach is undertaken, with one Egyptian University being examined.

\subsubsection{The Case study of Mansoura University, Egypt}

Mansoura University was established in 1972 under the name East Delta University but had existed as a branch of Cairo University since 1962 and is now one of 24 State owned Universities within Egypt. Currently, the university employs more than 6300 academic staff, and has more than 99,000 students (Mansoura University website: www.mans.edu.eg, 2015).

The Faculty of Commerce at Mansoura Universityis the subject of examination in this study. The faculty was established in the 1970s and currently educates more than 20,000 student each year and employs approximately 179 academic staff, of which are $70 \mathrm{PhD}$ holders (Faculty of Commerce website: www.comfac.mans.edu.eg, 2015).

After the civil revolution in Egypt in January 2011 a small number of academic staff at the institution established a Facebook group for the purpose of networking and KS within the Faculty to assist in the development and enhancement of Higher Education (HE) within the university. Currently this group has 90 members.

\subsection{Research population and sample}

The population of the study included all academic staff working in Higher Education (HE) institutions in Egypt. The size of the population exceeds 
50,000 (Ministry of Higher Education, www.egy-mhe.gov.eg, 2015) and include the academic ranks of professors at the top, and down to demonstrators at the bottom of the rankings.

The sampling frame for the study included all academic staff at the Faculty of Commerce holding a $\mathrm{PhD}$ degree, with their number approximating 70 working member. Due to limitations in time, cost, and effort, the researcher interviewed 32 participants using convenient approach to reach them and to ensure the participation of senior officials such as Head of Departments, Deputy Deans, and the Dean, as well as normal academic staff not holding any official administrative position.

\section{Research Hypotheses}

The study assumes the following hypotheses in relation to its research question. Notably, they are formulated in a non-statistical format since the study follows the qualitative inductive approach. They will not be tested statistically, but rather a qualitative narrative method will be used to attest them using a series of semi-structured interviews with academic staff at the case study of this research.

Hypothesis 1)There is no existence of a formal KS strategy within Mansoura University (Faculty of Commerce) using SNs;

Hypothesis 2) There is no acceptance of use of SNs among academic staff at Mansoura University (Faculty of Commerce) for the purpose of knowledge sharing;

Hypothesis 3) There are no motivations for using SNs among academic staff at Mansoura University (Faculty of Commerce) for the purpose of knowledge sharing.

\subsection{Interviews and data collection}

The researcher used the case study interviews, which Gray (2009) defines as a conversation between people, whereby one party assumes the role of the researcher. According to Hair et al. (2007) this method is helpful where issues are complex as it enables the researcher to receive feedback. Semistructured interviews were conducted with participants enabling the researcher to explore and investigate opinions from respondents, giving them the opportunity to both analyse in-depth and expand upon their answer (Gray, 2009). This method appeared to be suitable as it elicits the assumptions and stories participants hold about the issues under consideration and help in testing the study's hypotheses and assumptions. 


\subsection{Data analysis}

A total of 32participants from Mansoura University in Egypt were interviewed using open-ended questions and consisted of 3 Deputy Deans (DD), 4 Heads of Department (HD), 5Academic Heads (AH) and 20 academic staff (AS). The interview results were analysed using narrative analysis. This method is defined by Saunders et al. (2009) as 'an account of experience that is told in a sequential way, indicating a flow of related events that, taken together, are significant for the narrator and which convey meaning to the researcher.' This method allows the stories people employ in recounting events to be emphasized and analysed. The advantages of this method include factors such as its expedient nature and the way it allows an examination of the social background of the interviewee, the relationship between individuals and the interviewee's views of the organisation (Smith et al., 2008).

\section{Results}

Based on the empirical investigation of the case study, several important findings emerge from elementary descriptive data analysis, narrative analysis, debriefing of the interviewees, and interviews transcripts in relation to the study's question and hypotheses. These findings are presented hereafter.

\subsection{Existence of a KS strategy}

From the interviews, it appears that a contradiction exists regarding the existence of a KS strategy within Mansoura University Faculty of commerce. Some interviewees for example, claim there is no strategy for $\mathrm{KS}$ within the University whilst others consider a strategy does exist under an alternative name. Largely those further down the organisation hierarchy consider a strategy does exist indicating a lack of clarity, a lack of communication or a desire for interviewees to appear to be aware of potential strategies of which they have no knowledge.

The Deputy Dean did however state:

"There is no particular strategy, but I think there are recognizable priorities for KS." (DD.2)

This may therefore lead to others to believe that these priorities represent the KS strategy within the organisation. The Deputy Dean also stated that such a strategy was imperative in the future, reflecting the acceptance of the need 
for a KS strategy. Two senior managers did however identify the need to focus on informal not formal KS providing an indication of some awareness of KM approaches and strategies.

With regard to the corresponding hypothesis, it appears that there is no formal strategy for using SNs for the purpose of $\mathrm{KS}$, hence accepting the $1^{\text {st }}$ hypothesis of the study.

\subsection{Acceptance of use}

All interviewees agreed that SNs could have a large role in future KS, and particularly for the dissemination of knowledge, between staff or between staff and students to the extent that:

"People feel free and relax when they express their views through this medium more than face to face communication" (HD.1)

In terms of barriers to use SNs, the issues of bullying, security, privacy and trust emerged.

Also, some concerns were often expressed by staff relating to the unimportance of SNs:

"There are a lot of issues raised on SNs that are trivial and to read or comment on it is just wasting time". (AS5).

Through the interviews it became clear that the use of SNs is typically associated with negative images and culture in the minds of some people generally as a reflection of religious views within the region:

"The negative culture of the users of SNs is a big barrier for use" (AS1)

In practice this means that if you are using SNs you are immoral and this is especially the case for female users. This view is reflected by the manner in which most female academic users do not put their real pictures on the sites and are currently underrepresented on SNs. Within Mansoura University group on the Facebook which attracted 123 members of staff, only five of the forty female members put their own photo on the site and of these three are with their husbands. This was expressed by one of the female members of academic staff who said that:

".... One of the most serious issues for female users is the privacy”. (AS9).

Thus it can be concluded that the lack of acceptance of SNs within both institutions is the result of a lack of technological skill (linked to age), concerns relating to bullying or inappropriate comments, issues of privacy, 
trust and security, and, the ambiguity of perceived benefits aside from social relationships. The issues of age and gender are important considerations within the context of SNs and can be difficult to measure due to the nature of these groups where females and elderly members of staff are underrepresented either due to the familiarity with the technology or due to the threat of privacy. Issues of gender are likely to be directly linked to religious, cultural and social norms within Arab states and therefore may continue to exist or take time to change as political and social change occurs within the region. Issues of gender may also be linked to age as due to these sites only recently entering the Arab world, younger generations are more conversant and comfortable with them and this may result in greater acceptance as the technology and population matures.

Apparently, there is a mixed view towards accepting SNs as a tool of KS amongst academic staff at Mansoura university, but the majority of participants indicated that in the absence of a formal strategy adopted by senior management, using SNs will only waste time and escalate problems rather than solve them, hence accepting the $2^{\text {nd }}$ hypothesis of the study.

\subsection{Motivation for use}

In terms of motivation for use within Mansoura University, where some use of SNs is already occurring and common as indicated by one interviewees who did consider the social aspect of SNs to be useful for KS:

"SNs are useful in increasing the social bond of the staff which increases job satisfaction and makes the work environment more likable" (AS3).

Furthermore, the existing use of SNs appears to a greater understanding of potential benefits as all interviewees agree that Mansoura University is already benefiting from SNs use. These benefits vary from networking, global KS, speed of communication, constructive feedback, supporting innovation, generating new ideas, mass opinion polling cheaply, developing more social/collaborative views of learning, improved motivation, engagement, creating a connection to real-life learning and finally flexibility of use as one of the interviewees commented:

"SNs technology is already available free of charge to many people either at home, work or even while they are on move.

This makes it very easy and quick to use" (AS7). 
The existing use within Mansoura University also highlights the role that senior managers play in motivating staff to use such sites as whilst senior managers consider that SNs can act as a sensor to evaluate the popularity of their decisions and as a way to disseminate information to staff:

"SNs are a good way to know the problems within the school and respond to it quickly" (AH5).

However from observation of the Mansoura University group within Facebook and the interviews undertaken it would appear that the contributions from senior managers are relatively limited and this is noticed by staff:

I felt that the use of SNs by senior management within the school is just as a public-relations tool rather than a means of communication and solving people problems" (AS11).

It would appear that this lack of contribution is considered to also indicate a lack of commitment from senior managers and this is considered by academic staff to result in confusion and a lack of clear direction:

"Lack of purpose and clarity of common goals of using these websites in terms of the conflict of the nature of use ........ will continue in the future until we have more commitment from both senior management and academic staff" (AS18).

To conclude it is clear that there are no clear policies in place within either institution to adopt and use SNs as a KS tool however the organic growth of a community of this nature within Mansoura would appear to suggest that the institution is in the early stages of adoption and may be of significance in the future.

It is also clear from the results that Arabic culture and social norms play important roles in the use of SNs within developing and Arab countries. Females tended to be more concerned about online privacy than males. There is, nonetheless, a general acceptance and recognition that SNs encourage and enable discussion, communication and KS, hence rejecting the $3^{\text {rd }}$ hypothesis of the study.

\section{Discussion}

From the findings it is clear that Mansoura University, as represented by the Faculty of commerce, is at an early point of development in terms of SNs usage, KS strategy and technology usage. This therefore appears to highlight the importance of senior management support, as identified in the 
literature, for achieving the use of SNs for KS. Table 1 summarises the findings in terms of distribution of responses in relation to the three hypotheses of the study. The table depicts the numbers of respondents agreed or disagreed to the notions presented in the study hypotheses, and therefore leading to rejecting or accepting them.

The issues of privacy, trust and openness seem to be prevalent. This interestingly relates to concerns identified in the previous literature but there is also a cultural dimension relating to issues of gender that are evident within Arab nations as a wider cultural issue. This consideration is not one which has been given a great deal of attention within the area of SNs literature as the majority of previous studies focus upon the role of SNs within the developed world; largely within the USA and UK.

In relation to privacy and trust, as within previous studies, there appear to be a number of concerns relating to the informal nature of SNs and the manner in which users are required to combine personal and professional profiles. In addition it would appear that the inclusion of "social" within the name of such tools gives users a sense that the sites are not serious and cannot be used for work. This therefore suggests that the name of the site is value laden and represents a barrier to use.

Technological barriers appear to be present but are to some extent related to age. Increased barriers to use relating to technology may exist more due to the nature of the organisation, its culture and strategy than necessarily in relation to individual usage although previous literature has suggested that age may be a factor.

Overall the findings appear to suggest that the higher usage of SNs within Egypt does result in a greater acceptance and understanding of the role that SNs could play in KS.

Table 1: Summary of the findings and hypotheses testing

\begin{tabular}{|l|c|c|c|c|c|}
\cline { 2 - 6 } \multicolumn{1}{c|}{} & \multicolumn{2}{|c|}{$\begin{array}{c}\text { Participants } \\
\text { agreed }\end{array}$} & \multicolumn{2}{c|}{$\begin{array}{c}\text { Participants } \\
\text { disagreed }\end{array}$} & $\begin{array}{c}\text { Hypothesis } \\
\text { accepted / } \\
\text { rejected }\end{array}$ \\
\cline { 2 - 6 } & Count & $\%$ & Count & $\%$ & \\
\hline Hypothesis 1 & $\mathbf{2 3}$ & $\mathbf{7 1 . 8 \%}$ & $\mathbf{9}$ & $\mathbf{2 8 . 2 \%}$ & Accept \\
\hline Hypothesis 2 & $\mathbf{1 8}$ & $\mathbf{5 6 . 3 \%}$ & $\mathbf{1 4}$ & $\mathbf{4 3 . 7 \%}$ & Accept \\
\hline Hypothesis 3 & $\mathbf{8}$ & $\mathbf{2 5 \%}$ & $\mathbf{2 4}$ & $\mathbf{7 5 \%}$ & reject \\
\hline
\end{tabular}




\section{Conclusions}

This research has explored the role of using SNs for KS in university education in a developing Arab country, i.e. Egypt. The study found that there are contradictions and differences in viewpoints concerning the application of SNs as a KS tool and therefore factors which act as both barriers and drivers to usage within university education. There is a clear evidence of the need to ensure that formal KS strategies are put in place and for this to be achieved greater senior official support will be vital.

Within Mansoura University the manner in which SNs adoption is already occurring and SNs are considered to be valuable for KS particularly demonstrates the advantages that can be gained. Potentially the sharing of this best practice within and between the other HE institutions considered here and more widely than this may be one way in which the promotion of KS strategies and SNs could be achieved. This would be particularly effective if SNs was the vehicle used to promote such activities as it would demonstrate the manner in which SNs enable institutions to create global communities conveniently and cheaply.

Using SNs as the vehicle to share best practice would not however overcome the barriers that exist due to lack of technological and IT skills. It is expected that as the technological infrastructure is more fully developed,it will become more technologically capable however it will be important that technology is highlighted within the university and where possible training, assistance and the promotion of technology as a tool to assist in KS will be undertaken. This, to some extent will depend upon budget constraints and wider investment within the country. It may however be possible for the university to make use of mobile technologies, which are usually more reliable and available throughout the country, to demonstrate the use of SNs and the ease of use of such technology, particularly to older staff that it appeared were less accepting of technology use than younger staff.

Whilst senior management support and technological barriers should be relatively easy to overcome, the issues of privacy and trust, particularly relating to cultural and social norms within the region will be harder to overcome. Again the development of best practice groups and exposure to SNs will undoubtedly alleviate some of these concerns, particularly if privacy settings and user controls are explained and a recommendation for appropriately sensitive privacy settings can be provided. Furthermore if a university-wide approach were to be taken and agreement concerning 
pictures and personal details to be included were agreed by all affected groups, but to be implemented by all staff, this may assist in both exposing individuals to and determining the appropriateness of SNs use within the university. Once again the sharing of best practice between institutions may be useful in enabling issues such cultural and social norms to be discussed and previous experience by some may be promote future usage by others through discussion of concerns and the manner in which these may have already been overcome within another institution.

Overall there was broad agreement that there were advantages to employing such sites, given that SNs aim to facilitate KS amongst users. The research therefore concludes that HE universities should adopt SNs and draw upon their benefits as a KS tool. Additionally, for effective change the institution should work to achieve clear communication amongst staff and implement strategic plans to encourage the KS during working hours. The time has come for the institutions not only to dispel the ignorance of SNs but also to make academic staff aware of their necessity. The adoption of new strategies to seize SNs is an absolute must - to the irrefutable benefit of senior staff in their bid to accomplish an elevated echelon of communication with all other affiliates of their institutions.

\section{Recommendations for future research}

Based on the findings of the study, the following recommendations and themes are put forth for future research tackling the issue of using modern technologies for knowledge sharing in higher education.

1. The antecedents, drivers and barriers to using web technologies and SNs in knowledge management.

2. Behavioural intention formation for knowledge sharing and knowledge management.

3. Is higher education ready for knowledge management?

4. Overcoming cultural barriers to knowledge sharing in the Arab World.

5. The role of Social Networks in active learning in higher education.

6. The impact of using SNs as a KM tool on the quality of HE services.

7. A comparison between private and public university adoption of modern web technology in knowledge management and knowledge sharing. 


\section{References}

Ardichvili, A., Page, V. \& Wentling, T. (2003) Motivation and barriers to participation in virtual knowledge-sharing communities of practice, Journal of Knowledge Management, 7, pp164-177

Barnes, S. (2007) A privacy paradox: Social networking in the United States, [Online], http://www.firstmonday.org/issues/issue11_9/barnes/index.html [Accessed 01/06/08]

Berg, B. (2009) Qualitative Research Methods For the Social Sciences, 7th edition, Pearson Education Company: USA

Boyd, D. \& Ellison, N. (2007) Social Network Sites: Definition, History, and Scholarship, Journal of Computer-Mediated Communication, No.

[Online], http://jcmc.indiana.edu/vol13/issue1/boyd.ellison.html [Accessed $17 / 05 / 10]$

Cain, J. (2007) Online Social Networking Issues within Academia and Pharmacy Education, American Journal of Pharmaceutical Education, No. $\quad 72$ [Online], http://findarticles.com/p/articles/mi_qa3833/is_200801/ai_n243946 83/pg_1?tag=artBody; col1 [Accessed 15/05/08]

Creswell, J. (2009) Research Design: qualitative, quantitative, and mixed methods approaches, SAGE Publications, Inc: USA

Creswell, J. \& Clark, V. (2011) Designing and conducting mixed methods research, SAGE Publication, Inc: USA

Donath, J. (2007) Signals in Social Supernets, Journal of ComputerMediated Communication, No. 13, pp231-251

Dwyer, C., Hiltz, S. \& Passerini, K. (2007) Trust and Privacy concerns within social networking sites: A comparison of Facebook and MySpace, [Online], http://csis.pace.edu/ dwyer/research/DwyerAMCIS2007.pdf [Accessed 01/06/08]

Ellison, N., Gibbs, J. \& Weber, M. (2015), The use of Enterprise Social Network Sites for Knowledge Sharing in Distributed 
Organizations: The role of organizational affordance, American Begavioural Scientist, Vol. 59, No. 1, pp. 103-123.

Faculty of Commerce, Mansoura University, www.comfac.mans.edu.eg, accessed: April, 2015

Facebook. (2014) Facebook: My Account - Primary Language, [Online], https://www.facebook.com/\#!/editaccount.php?language [Accessed 13/03/2014]

Forkosh-Baruch, A. \& Hershkovitz, A., (2012), A case study of Israeli higher-education institute sharing scholarly information with the community via social networks, Internet \& Higher Education, 15, pp. 58-68

Garcia, E., Elbeltagi, I, Al-Husaini, S \& Abdelkader, A., (2011), Evaluating the use of Social Networking Sites as a Tool for Knowledge Sharing for Developing Higher Education in Developing Countries: An Exploratory Study of Egypt and Iraq, Proceedings of the 10th European Conference on e-Learning, Brighton Business School, University of Brighton, UK, 10-11 November 2011.

Gray, D. (2009) Doing research in the real world, SAGE Publication Ltd: London

Hair, J., Money, A., Page, M. and Samouel, P. (2007) Research Methods for Business. West Sussex: John Wiley \& Sons (UK).

Hewitt, A. \& Forte, A. (2006) Crossing Boundaries: Identity Management and Student/Faculty Relationships on the Facebook, [Online], http://www-

static.cc.gatech.edu/ aforte/HewittForteCSCWPoster2006.pdf [Accessed 01/06/08]

Hildreth, P \& Kimble, C. (2002) The duality of knowledge, Information Research, Vol. 8, No. 1

Jones, H \& Soltren, H. (2005) Facebook: Threats to Privacy, [Online], http://groups.csail.mit.edu/mac/classes/6.805/student-papers/fall05papers/facebook.pdf [Accessed 19/05/08]

Liao, S., Chang, J., Cheng, S. \& Kuo, C. (2004) Employee relationship and knowledge sharing: A case study of a Taiwanes finance and securities firm, Knowledge management and practice, vol.2, pp24 34 
Lin, S.W., \& Lo, L. (2015), Mechanisms to motivatr knowledge sharing: integrating the reward systems and social networks perspectives, Journal of Knowledge Management, Vol. 19, No. 2, pp. 212-235

Mansoura University, www.mans.edu.eg, accessed: April, 2015

Mathew V. (2010) Service delivery through knowledge management in higher education, Journal of knowledge Management practice, vol.11. no. 3, pp1-14

McConnell, B. (2008) Social Networks, from 80s to the 00s, [Online], http://gigaom.com/2008/01/20/social-networks-from-the-80s-tothe-00s/ [Accessed 15/05/08]

Ministry of Higher Education, www.egy-mhe.gov.eg, Accessed: April, 2015.

Nonaka I. O. \& Takeuchi, H. (1995) The knowledge-creating company: how Japanese companies create the dynamics of innovation, Oxford University Press: New York.

Northwestern

University

in

Qatar, (http://menamediasurvey.northwestern.edu), [Accessed: May 2015]

OFCOM. (2008) A quantitative and qualitative research report into attitudes, behaviours and use, [Online], http://www.ofcom.org.uk/advice/media_literacy/medlitpub/medlitp ubrss/socialnetworking/report.pdf [Accessed 03/05/08]

Sandberg, S. (2009) How many friends can you have? [Online], https://www.facebook.com/blog.php?post=72975227130

[Accessed 13/06/11]

Saunders, M., Lewis, P. \& Thornhill, A. (2009) Research Methods for Business Students, Pearson Education Limited: England

Schonfeld, E. (2009) Zuckerberg on who owns user Data on Facebook: it's Complicated, [Online], http://technews.am/conversations/techcrunch/zuckerberg_on_who_ owns_user_data_on_facebook_it_s_complicated [Accessed $13 / 06 / 11]$

Schutt (2003) The post-Nonaka Knowledge Management - Proceedings of IKNOW 03, 3rd International Conference on Knowledge Management - Graz -Austria - 290-301. 
Siggelkow, N. (2007) Persuasion with case studies, Academy of management Journal, vol.50 no.1, pp20-24

Smith, M., Thorpe, R. \& Jackson, P. (2008) Management research, Sage Publication Ltd: London

SPOT ON PR. (2010) Middle East \& North Africa Facebook Demographics - May 2010, [Online], http://www.spotonpr.com/wpcontent/uploads/2010/05/FacebookMENA_24May10.pdf [Accessed 11/06/11]

Suarez, D. (2007) When students choose the challenge, Educational Leadership, Vol. 65, No. 3, pp. 60-65.

Torres, L. P., Marques Siqueira, L.M., \&Matos, E. L, (2013), Social Networks as a means of sharing open educational resources in Higher Education, Revista Dialogo Educational, Vol. 13, No. 38, oo. 183, 201.

Yin, R. (2009) Case study Research- Design and Methods, 4th Edition, SAGE Publications, Inc: Los Angeles 